\title{
Twelve Contiguous Spinous Process Fracture of Cervico-Thoracic Spine
}

\author{
Seong Rok Han, Moon Jun Sohn \\ Department of Neurosurgery, Ilsan Paik Hospital, Inje University College of Medicine, Goyang, Korea
}

The clay-shoveler's fracture is an isolated avulsion fracture of the lower cervical or upper thoracic spinous process. Among them, multiple spinous process fractures are very rare. We present 34-year-old male patient who have multiple spinous process fractures with twelve contiguous levels of cervico-thoracic spine (from C4 to T8) after motorcycle accident. This case is multiple isolated spinous process fractures with good clinical outcome.

Key Words: Clay-shoveler's fracture $\cdot$ Spinous process $\cdot$ Avulsion fracture

\section{INTRODUCTION}

Clay-shoveler's fracture is isolated spinous process avulsion fracture classically observed in the lower cervical or upper thoracic spine. This type of fracture is most common in those who engaged in hard physical labor ${ }^{3,6,7}$. Recently, several cases of isolated spinous process fractures that are caused by motor vehicle accidents or sports injuries have been reported (Table 1). Isolated spinous process fractures are most common at the level of T1, followed by C7, T2, T3, and $\mathrm{C}^{1,7}$. Among them, multiple spinous process fractures are very rare ${ }^{1)}$. We present a case of multiple isolated spinous process fractures with twelve contiguous levels of the cervico-thoracic spine, which extended from C4 to T8. To the best of our knowledge, this case is the most multiple spinous process fractures so far reported in the literatures.

\section{CASE REPORT}

A 34-year-old man was transferred our hospital from local clinic after motorcycle accident. Physical examination revealed

- Received: June 11, 2014 • Revised: August 15, 2014

- Accepted: August 20, 2014

Corresponding Author: Seong Rok Han, MD, PhD

Department of Neurosurgery, Ilsan Paik Hospital, Inje University, 170

Juhwa-ro, Ilsan-Seo-gu, Goyang 411-410, Korea

Tel: +82-31-910-7730, 5237, Fax: +82-31-915-0885

E-mail: hsrkmj@paik.ac.kr

$\otimes$ This is an Open Access article distributed under the terms of the Creative

Commons Attribution Non-Commercial License (http://creativecommons.org/ licenses/by-nc/3.0/) which permits unrestricted non-commercial use, distribution, and reproduction in any medium, provided the original work is properly cited. an extensive tenderness from the posterior neck to upper back. Neurological examination was normal. Initial spine X-rays showed multiple spinous process fractures in the cervico-thoracic spine. Computed tomography (CT) scanning of the cervicothoracic spine showed twelve contiguous spinous process fractures ranged from $\mathrm{C} 4$ to $\mathrm{T} 8$ (Fig. 1A, B). Cervico-thoracic spine magnetic resonance images (MRI) revealed that spinal cord was normal and there was no additional soft tissue injury (Fig. 1C). The patient was treated conservatively, which included analgesics and muscle relaxants. Immobilization was maintained for 4 weeks with cervical collar and thoraco-lumbar brace. After 3 months, we evaluated follow-up cervico-thoracic CT scanning which didn't show union of spinous process fractures yet. After 6 months follow-up, visual analogue scale score was gradually improved from 6 to 1 . The patient showed no neurological deficits also.
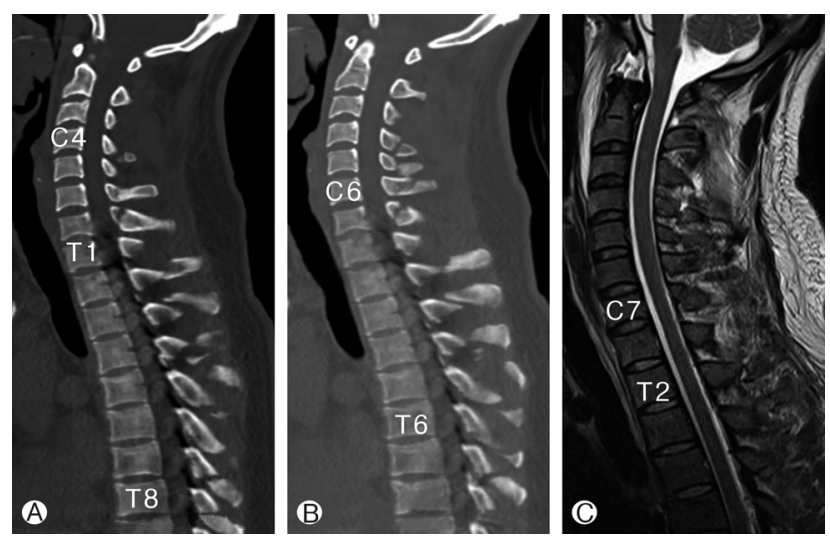

Fig. 1. Initial cervico-thoracic sagittal CT scans (A and B) show twelve adjacent spinous process fractures, which extended from C4 to T8. T2-weighted sagittal cervical MRI (C) reveals contiguous spinous process fracture without any spinal cord injury. 
Table 1. Summary of patients with isolated spinous process fractures in the literatures

\begin{tabular}{lcll}
\hline \hline Author & Age/Sex & Spinous process fracture level (Number) & Etiology \\
\hline Akhadder $\mathrm{A}^{1)}$ & $40 / ?$ & $\mathrm{~T} 2,3,4,5,6,7,8(7)$ & Automobile accident \\
Kaloostitan $\mathrm{PE}^{2)}$ & $14 / \mathrm{M}$ & $\mathrm{T} 1(1)$ & Indoor rock climbing \\
Kang DH $^{3)}$ & $40 / \mathrm{M}$ & $\mathrm{T} 1,2(2)$ & Golf player \\
Kim SY) & $45 / \mathrm{F}$ & $\mathrm{C} 6,7(2)$ & Golf player \\
Kose $\mathrm{K}^{5)}$ & $58 / \mathrm{M}$ & $\mathrm{T} 5,6,7,8,9,10(6)$ & Automobile accident \\
Omurganin $\mathrm{S}^{6)}$ & $32 / \mathrm{M}$ & $\mathrm{C} 6,7(2)$ & Automobile accident \\
Umredkar $\mathrm{A}^{7)}$ & - & $\mathrm{C} 6,7, \mathrm{~T} 1,2,3,4(6)$ & Automobile accident \\
Unay K & $39 / \mathrm{M}$ & $\mathrm{C} 7, \mathrm{~T} 1(2)$ & Osteoporosis \\
Our case & $34 / \mathrm{M}$ & $\mathrm{C} 4,5,6,7, \mathrm{T1}, 2,3,4,5,6,7,8(12)$ & Motorcycle accident \\
\hline
\end{tabular}

\section{DISCUSSION}

Clay-shoveler's fracture may occur through direct trauma on the flexed spine or through shear forces ${ }^{2-7}$. It can be occurred in hyperextension, hyperflexion, or rotation of neck ${ }^{2,47}$. Muscle and ligamentous stress is transmitted through the supra-spinous ligaments and results in an avulsion fracture of the spinous processes ${ }^{2}$. Our case is an unusual example for multiple spinous process fracture that can be produced by several mechanisms, such as a direct blow to the posterior aspect of lower neck and the thorax, upper back hyperextension, and hyperflexion injuries against the supraspinous ligament after motorcycle crash.

An useful imaging study for this fracture is radiography, ${ }^{3,6,7)}$. A double spinous process sign at the affected level can be detected on simple antero-posterior radiographs ${ }^{6,9)}$. Downward displacement of fractured spinous process fragments (spinolaminar breach sign) can be seen on lateral radiograph views, ${ }^{3,6,7}$. Isolated spinous process fracture considered as a warning sign for more severe spinal injury, so it should be evaluated carefully to detect more severe spinal injuries ${ }^{7}$. CT and MRI of the cervical and thoracic spine may be useful for detecting more serious spine fractures and further injuries to surrounding structures including spinal cord and ligament ${ }^{3,6)}$.

These injuries are known to be stable but painful. Generally, this type of fractures are treated conservatively without the need for surgical intervention ${ }^{3,5,8)}$. Immobilization and restriction of physical activity for 4 to 6 weeks generally result in good outcome $e^{3,8}$. Our patient shows good clinical outcome after 4 weeks immobilization and restriction of physical activity.

\section{CONCLUSION}

We report a case of twelve isolated spinous process fracture of the cervico-thoracic spine after motorcycle accident. This case is multiple isolated spinous process fractures with good clinical outcome.

\section{REFERENCES}

1. Akhaddar A, El-asri A, Boucetta M: Multiple isolated thoracic spinous process fractures (Clay-Shoveler's fracture). Spine J 11(5): 458-459, 2011

2. Kaloostian PE, Kim JE, Calabresi PA, Bydon A, Witham T. Clayshoveler's fracture during indoor rock climbing. Orthopedics 36(3):e381-383, 2013

3. Kang DH, Lee SH: Multiple spinous process fractures of the thoracic vertebrae (Clay-Shoveler's Fracture) in a beginning Golfer: a case report. Spine (Phila Pa 1976) 34(15):E534-537, 2009

4. Kim SY, Chung SK, Kim DY: Multiple cervical spinous process fractures in a novice golf player. J Korean Neurosurg Soc 52(6): 570-573, 2012

5. Kose KC: Case report: the impact of pseudoarthrosis on clinical outcome in isolated spinous process fractures of six adjacent level thoracic vertebrae. Med Gen Med 8(1):67, 2006

6. Solaroğ?lu I, Kaptanoğlu E, Okutan O, Besknnakli E: Multiple isolated spinous process fracture (Clay-shoveler's fracture) of cervical spine: a case report. Ulus Travma Acil Cerrahi Derg 13(2): 162-164, 2007

7. Umredkar A, Sura S, Mohindra S: Multiple contiguous isolated spinous process fracture (Clay-Shoveler's fracture) of the cervicodorsal spine. Neurol India 59(5):788-789, 2011

8. Unay K, Karatoprak O, Sener N, Ozkan K: A clay-shoveler's fracture with renal transplantation and osteoporosis: a case report. J Med Case Rep 2:187, 2008

9. Yamaguchi KT Jr, Myung KS, Alonso MA, Skaggs DL: Clay-shoveler's fracture equivalent in children. Spine (Phila Pa 1976) 37(26): E1672-1675, 2012 